in the higher vertebrates is " heat," but in very few is this accompanied by a discharge of blood, and where there is a slight staining the proportion of red blood corpuscles to white is very small, as in those macaque monkeys observed by Heape of Cambridge. In the case of "Johannah," the famous chimpanzee, whose menstrual history I have recorded elsewhere, I made a careful microscopical examination of the menstrual discharge and satisfied myself that the red corpuscles were comparatively small in number, though enough to tinge distinctly and to stain red the monthly flow; still, all these were under the artificial surroundings of captivity. Not only the attendant pain and copious loss in woman but the general and nervous disturbances occurring at these times are suggestive of a departure from the originally normal line. The amenorrhcea accompanying lactation is often regarded by women as a welcome condition of security from impregnation. This we know to be an error, for ovulation is proceeding with its accustomed regularity and impregnation may, and often does, take place. Furthermore, the development of the endometrium every month may be safely regarded as the preparation of the uterus for the implantation of an impregnated ovum and the menstruation may be considered as evidence of a failure of these anticipations.

It is quite likely that primitive woman never menstruated, at any rate as we know menstruation to-day, and there is reason to believe that this phenomenon, this heritage of woman, of which she is not proud and for which she is not grateful, has assumed its present proportions as a result of the almost universal practice, begun in the earliest ages, of restraining the excessive uberty of our primeval ancestors.

Curzon-street, W.

\section{A CASE OF}

\section{CHRONIC INTESTINAL OBSTRUCTION WITH PERFORATION OF THE SIGMOID FLEXURE.}

\section{BY GEORGE A. CLARKSON, F.R.C.S. EYG.}

THE notes of the following case present one or two points of considerable interest. At the time of the first operation the history and the age of the patient led me to believe that I was dealing with a stricture of some part of the colon due to growth but the distension of the small intestine and cæcum was so great and the call for immediate drainage of the distended bowel was so urgent that no prolonged examination of the colon could be made. The subsequent sloughing and perforation of the sigmoid flexure probably occurred at the seat of obstruction, yet here no cause was obvious to account for the condition found. The gut, though in a condition little short of gangrene, was apparently not invaded by growth and the fact that no fæcal matter was found in it rather excluded the idea that retention of a scybalous mass of fæces at that point had given rise to inflammatory softening and perforation of its coats.

The patient, a woman, aged 52 years, had suffered from disease of the outer surface of the acetabulum for 12 years and the sinuses on the outer side of the right hip had healed after a free exploration and scraping in May, 1903. In the spring of 1904 she began to be subject to occasional attacks of vomiting, accompanied by abdominal pain, distension, and constipation, but these attacks were relieved from time to time by aperients and enemata. On May 9th she was seized with a severer attack than usual. The bowels were at first relieved and the sickness would stop for 12 hours at a time but invariably returned again. The patient was kept in bed, put on a fluid diet, and saline aperients and enemata were given with some result. A rectal examination revealed no stricture within reach of the finger nor could anything be felt through the abdominal walls to localise the seat of obstruction. On the 15th the symptoms became urgent, the vomiting being persistent and copious but not offensive in smell, the abdominal distension became very great, and there was obviously more or less complete obstruction. Enemata given through a long rectal tube produced no effect, so the patient was removed without delay to a surgical home. The opera. tion was carried out in the evening. The abdomen was opened in the middle line below the umbilicus. Enormous distension of the small intestine and cæcum was met with and as the transverse and descending colon appeared less distended and the indication to drain the bowel with as little delay as possible was urgent the wound was closed and another small incision was made over the cæcum, which was drawn out, opened, and a Patul's tube tied in. Following the operation there was a little vomiting of a stercoraceous character but the caccal opening gave great relief and the acute symptoms subsided. At the end of a fortnight the patient was able to be removed home. Enemata were subsequently given from time to time and occasionally brought away small scybalous masses.

On the afternoon of June 11th the patient was suddenly taker ill with intense pain in the left inguinal region and when I saw her was extremely collapsed, with drawn features, cold extremities, and thready pulse. Subcutaneous injections of strychnine with a little morphine were given and she gradually rallied, symptoms of an acute localised peritonitis quickly manifesting themselves. A diagnosis of intestinal perforation was made and on the 15 th an incision similar to that for inguinal colotomy was made over the area of pain and resistance. On opening the abdomen some very foul-smelling pus welled up and the abscess cavity having been thoroughly swabbed out the sigmoid flexure was seen plastered over with thick lymph and with a perforation on its anterior surface of the size of a shilling. The coats of the bowel were softened, black, and gangrenous and in bringing it forward it tore almost across. The wound was therefore enlarged in an upward direction and the bowel was slit up with scissors till its walls appeared unaffected by the changes below and would allow of its being stitched to the skin which was then done. The whole condition seemed to be an acutely inflammatory one. The abscess cavity was again swabbed out and then packed with iodoform gauze, an indiarubber tube of large calibre being passed into the colon.

The patient stood the operation well. The discharge was most offensive for some days but the cavity contracted quickly and at the end of a month the opening differed but little from an ordinary colotomy opening and it acted well. As the crcal opening became an annoyance to the patient when she began to get about again owing to the liquidity of the discharge, on August 11th, under ether, the mucous membrane was separated from the skin and the opening closed. At the time of writing (March, 1905) the patient finds no difficulty in controlling the artificial anus and she is able to get about out of doors and to resume her ordinary domestic duties at home.

Leicester.

\section{Clinital 睯otes:}

MEDICAL, SURGICAL, OBSTETRICAL, AND THERAPEUTICAL.

\section{A NOTE ON THE ABDOMINAL INCISIONS FOR THE EXPLORATION OF THE APPENDIX AND PER-} FORATED ULCER OF THE STOMACH.

\section{By Curnbert S. Wallace, M.B., B.S. LoNd.} F.R.C.S. ENG.,

SURGEON TO OUT-PATIENTS AT ST, THOMASS HOSPITAL; ASSISTANT SURGEON TO THE EAST LONDON HOSPITAL FOR CHILDREN.

The incision for exploration of the appendix.-The two abdominal incisions that are most in vogue for removal of the appendix-namely, that of McBurney and that through the rectus sheath-have their advantages and disadvantages. The McBurney incision is cramped and if difficulties are encountered gives poor access even if strongly spanned by assistants. It is, on the other hand, easily and quickly closed. The rectus sheath incision gives a good view and can be enlarged without difficulty to any extent; it is, however, often difficult to close owing to the tendency of the layers behind the rectus muscle to retract towards the iliac crest. The following modification seems to combine some of the advantages of both incisions. The rectus sheath is entered towards its outer side by the usual vertical incision. The muscle is then retracted inwards and the posterior wall of the sheath is exposed. As a rule two nerves are seen running transversely inwards about one inch apart. The mid-point between these is selected and the 
peritoneal cavity is entered by an incision one inch long transverse to the body axis and parallel to the nerves. This incision is easily closed since the natural tension of the parts approximates the edges. Should difficulties be encountered in the removal of the appendix and a large incision be required it can be obtained by the usual vertical incision in the posterior rectus sheath.

The incision for perforated ulcer of the stomach.-In many cases of perforating ulcer of the stomach or the duodenum it is a matter of doubt as to whether the pelvis has become infected or not. Even after the usual epigastric incision the same doubt remains, since the state of the middle area of the abdomen is no criterion as to that of the lower portion. The only method of settling the point is by making an incision in the hypogastrium. Should this be made after the upper incision there is danger of infecting the pelvis if this prove clean, since hands and instruments are already soiled. It therefore seems advisable in cases of doubt to make the hypogastric incision first. The state of the pelris can then be ascertained and if found clean the wound can be closed. If the contrary prove to be the case the lower wound can be used in the process of cleansing the peritoneum. The primary lower incision is also of service in determining the condition of the appendix when there is doubt as to whether the appendix region or the upper part of the intestinal tract is at fault.

Upper Wimpole-street, $\mathrm{W}$.

\section{A CASE OF ACUTE IODINE POISONING WITH FATAL RESULT.}

By E. Donaldonon-Sim, M.R.C.S. ENG., L.R.C.P. Lond., SENIOR RESIDENT MEDICAL OFFICER AT THE GUEST HOSPITAL, DUDLEY.

A MAN, aged 52 years, was admitted to the Guest Hospital, Dudley, on the morning of Jan. 25th, 1905, with an outward dislocation of the right foot and a simple fracture of the right fibula. He had been a hard drinker for some years and was drunk at the time of the accident. There was no evidence of definite cardiac disease on examination of the heart and no anasarca was present. No specimen of the urine was obtained. The dislocation was reduced under chloroform soon after admission. On the morning of the $26 \hat{t}$ th the patient showed signs of threatening delirium tremens. He was placed on a bromide mixture and, of course, was on milk diet. He complained of pain in the left side of the chest but no sign of injury or disease was found on examination. Orders were given, however, to paint the painful area with liniment of iodine. When about to do this (at 7.30 P.M.) the nurse placed a bottle containing liniment of iodine on the patient's locker and then left the patient for certainly not more than a minute. During this short period, however, the patient seized the bottle of iodine, uncorked it, and gulped down the whole of the contents, about four ounces. I was in the ward at the time and hearing the other patients call out I turned round in time to see the patient replace the empty bottle on the locker. I at once took steps to wash out the stomach, but in order to do this we were forced to anæesthetise lightly the patient with chloroform. The stomach was then thoroughly washed out until the returning boric lotion was quite clear. On completion of this operation the patient promptly regained con sciousness, his pulse was good, and his condition seemed satisfactory. There was no dyspncea nor was there vomiting or purging. In about an hour's time the pulse became very feeble, the extremities were cold and blue, and the face was cyanosed: respiration was easy kut the patient kept expectorating and complained of some pain in the epigastric region. Five minims of solution of strychnine were injected hypodermically and repeated in two hours as there was no improvement. Hot water bottles were applied and one ounce of brandy was given per rectum. Two drachms of bicarbonate of sodium were given by the mouth in a little water and diluent drinks were ordered. In spite of treatment, however, the patient died from cardiac failure at 11.45 P.M. The coroner, unfortunately, did not order a post-mortem examination to be made.

The case is of interest on account of the rarity of acute iodine poisoning and on account of the rapidity with which death followed the swallowing of the poison in spite of nergetic treatment. Probably this was partly due to the atient having been in a low condition of health on account f his drunken habits.

Dudley.

\section{de}

\section{HOSPITAL PRACTICE, BRITISH AND FOREIGN.}

Nulla autem est alia pro certo noscendi via, nisi quamplurimas et morborum et dissectionum historias, tum aliorum tum propria collectas habere, et inter se comparare.-MoBGAGNI De Sed. et Caus. Morb., lib. iv., Procmium.

\section{POPLAR HOSPITAL.}

A CASE OF SEROUS PLEURAL EFFUSION FOLLOWING ACUTE RHEUMATIC ARTHRITIS AND PERICARDITIS.

(Under the care of Dr. CECIL W ALL.)

For the notes of the case we are indebted to Mr. A. C. Dixon, house physician.

A man, aged 44 years, was admitted into the Poplar Hospital under the care of Dr. Cecil Wall on August 19th, 1904. The patient had been ill for 14 days with acute rheumatic arthritis. There was nothing of importance in his previous history or in his family history; he had not previously suffered from rheumatism. On admission his temperature was $102 \cdot 4^{\circ} \mathrm{F}$.; many joints were hot, red, tender, and swollen, and there was much sweating. The heart was not enlarged but a systolic murmur was heard at the apex and in the axilla accompanying a weak first sound. He was put on full doses of salicylate of sodium and the temperature fell rapidly and reached normal on August $22 n d$. On the 23 rd the temperature rose to $100^{\circ}$ and loud to-and-fro pericardial friction was heard; during the next few days the temperature continued to rise and reached the maximum of $104^{\circ}$ on the 29th. Between these two dates a large pericardial effusion developed and the patient became delirious. After the 29th the temperature began to fall and the pericardial effusion to lessen. On Sept. 6th the area of cardiac dulness was only slightly larger ti an normal but for some days the temperature remained between $100^{\circ}$ and $101^{\circ}$. On Sept. 7 th and 10th the patient had syncopal attacks from which he recovered under the influence of stimulants. Between the 6th and the 15th the pyrexia continued, there was a good deal of diarrhœa, and the patient sank into a typhoid state. Tested on Sept. 14th the blood did not give Widal's reaction. On the 13th signs of pleurisy at the right base developed and an effusion formed of which 29 ounces were evacuated on the 16th. A report upon this fluid is appended. The temperature now gradually fell to normal and on the 20th there was no evidence of pleurisy or of effusion on the right side. Pleural friction, however, was heard in the left axilla. At the beginning of October a fresh effusion formed in the right pleural cavity and 11 ounces were removed by aspiration on Oct. 4th. The signs, however, at the right base persisted and the temperature again rose. An exploring syringe was again inserted on the 21st but only three ounces of fluid were obtained. After this the signs cleared up, the temperature became normal, and the patient made rapid progress towards recovery. He was discharged to a convalescent home on Nov. 22nd. On discharge and when seen about a month later the heart seemed a little enlarged but no murmurs could be heard. In all other respects he seemed perfectly well.

Report on the pleuritic fuid by Miss H. L. BILLETT of the Laboratory of Pathology and Public Health.--" Microscopical examination of the centrifugalised deposit from the fluid showed it to consist chiefly of red blood discs, with a fair number of leucocytes and a small number of endothelial cells. The blood discs are of good colour and the leucocytes appear to be chiefly of the polymorphonuclear type. The coagulum shows a similar composition with the addition of fibrin. No tubercle bacilli have been found in a stained specimen. Plate cultivations were made from the centrifugalised deposit, and an organism was isolated which is similar in microscopical appearance to the rheumatic diplococcus, appearing in pairs, groups, and 